\title{
AN OVERVIEW OF GRAMMAR THEORIES AND THEIR INFLUENCE ON EFL/ESL INSTRUCTION
}

\author{
Enriketa Sogutlu \\ Dr., University College Beder, Albania, esogutlu@beder.edu.al
}

\begin{abstract}
This paper is an overview of the impact of grammar theories on the instruction of English as a second or foreign language. It firstly presents a brief description of three major grammar theories: transformational grammar, cognitive grammar and construction grammar. It then describes and analyses how these theories and their paradigms have influenced EFL/ESL instruction, in particular the teaching of grammar knowledge and grammar constructs. Finally it concludes that developments in grammar theories have all had different impacts on EFL/ESL instruction and that knowledge of these theories may contribute to effective grammar instruction.
\end{abstract}

Keywords: EFL/ESL instruction, grammar theories, grammar knowledge, grammar instruction

\section{INTRODUCTION}

While generally used to refer to a variety of senses, the term "grammar" is most broadly understood as the description of the meaning and form of the sentences of a language or, in a narrower sense, as the description of its parts ranging from phonetics and phonology to syntax and morphology.

A variety of ways have been used to define grammar. While according to, according to Chomsky, the grammar of a language is the system of rules necessary to construct meaningful sentences $(1966 ; 1976)$, for many other linguists it is the combination of words (Givon, 2011) or the combination of phrases and structures and their relation to each other in a sentence (Chomsky, 1966; Radford, 1988; Lock, 1996; Greenbaum \& Nelson, 2009). Although differently formulated, at the basis of all these considerations lies the concept that grammar is the system of rules that determine how a particular language functions. Knowledge of this system contributes to the way verbal and oral communication is achieved.

Since grammar is a phenomenon that can be studied in the same way as physical movement and the human body are, then, the need arises for a theory concerned with its study. The two main tendencies of modern thought in languages and in grammar date back to ancient theoretical perspectives. According to the perspective of logic and philosophy, which has also been referred to as the formal approach (Lock, 1996; Mathiessen \& Halliday, 2009), language and grammar are a set of rules used to specify grammatical structures. In this approach, as it is considered the basic unit, the sentence is studied separately. According to the perspective of rhetoric and ethnography, referred to as the functional approach, grammar is a source for the creation of thought through words and the sentence is studied as part of the discourse (Lock, 1996; Mathiessen \& Halliday, 2009) because the basic unit in this view is the text. The formal and the functional approach differ in that the former focuses on the relationship between structures in a sentence while the latter focuses on how these structures are used to express meaning. 
There also exist different views concerning the purpose of grammar and its disciplines. From a traditional perspective, grammar's main aim has been morphology, that is the study of words; second syntax, the study of sentences in order to explain the different forms of words; and finally the meaning of these words was studied (Halliday M. A., 1994). Authors like Lock organize grammar based on rank, which includes words, groups of words, parts of the sentence, and class, which includes nouns, adjectives, verbs, and other categories (Lock, 1996). According to Chomsky (1976), grammar is a well-organized system, where each of its three disciplines: syntax, phonetics, and semantics, is a set of rules, and modifications of one part involve modifications of the other.

In addition to morphology and syntax, many other modern linguists (Natthan 2008; Kaplan \& Bresnan, 1995; Broderick, 1975; Radford, 1988) include semantics and phonology arguing that their inclusion gives grammar a broader and more complete meaning. Other linguists divide grammar into lexical and phonological categories (Marter as cited by Hurford and Hurford (2012). According to Talmy (2008) the division of language into grammatical and lexical occurs because each of these two systems has clear semantic functions, which are inseparable and complementary. There have also been suggestions that grammar consists of computer and schematic aspects of the mind and the brain (Mukherji, 2010).

However, knowing the rules of the language system is not sufficient. Chomsky's description of the maximum level of this recognition is "the innate ability of the ideal user" (Chomsky, 2015b, p. 4). Meanwhile Radford, inspired by Chomsky, defines grammar as "the model of the ability of a good native speaker" (1988, p. 42).To describe this ability, many linguists beginning with Chomsky (1966; 2015b) followed by Broderick (1975) and Radford (1988), use the term competence, which is knowledge of language, to distinguish it from performance, which is described as putting competence into practice. It is worth noting that performance is not always a true indicator of competence; in other words, the language user does not always manage to perfectly express knowledge about which he can have very clear ideas.

In terms of defining the grammar rules of a language, a distinction is made between the prescriptive and the descriptive approach. In the prescriptive approach, linguists define the rules of language, which are based on the historical stages that language has gone through, and thus give instructions on how to use language. In the descriptive approach, linguists collect spoken and written language samples, analyse the grammatical pattern of these samples, and issue rules regarding language usage. In other words, according to Huddleston and Pullum (2007), descriptive grammar tells us what language is like, while prescriptive grammar tells us how not to make mistakes when using it.

The different approaches to language and grammar have also had an impact on second/foreign language acquisition theories and on their instruction. This paper gives an overview of three grammar theories: the transformational grammar as a traditional and formal approach to language and grammar and the cognitive and construction grammars as more modern and functional approaches. It also provides an outline of these theories' influence and applicability to the teaching of grammar in the EFL/ESL context. it concludes that use of one theory does not exclude the others and a combination of their principles can contribute to the instruction of different language forms and constructs.

\section{TRANSFORMATIONAL GRAMMAR}

Transformational grammar was developed as a concept and theory by Noam Chomsky. It consists of two types of rules: the rules of phrase structure, according to which the sentence consists of a noun phrase and a verb phrase, and the transformational rules, which serve to transform sentences from affirmative to interrogative or from active to passive.

Transformational grammar is a specific theory within generative grammar, which dates back to the 1950s, the period when the cognitive revolution marked its beginnings. The influences of this revolution caused the attention in linguistics to pass from "the mechanics of structuring language to the mental process that characterizes its features" (Ohalla, 2001, p. 11).

Generative transformative grammar studies linguistic competence in order to describe the user's ability to create an infinite number of sentences. Unlike traditional grammars, which analyse the sentence based on words, transformative grammar does this analysis based on phrases. Each sentence has its own syntactic components which belong to certain categories within a hierarchical connection. (Radford, 1988; Broderick, 1975). Broderick (1975) even argues that the fact that this kind of grammar does not accumulate but generates constituent structures, is also why it is called a generative theory. Thus, the words this boy, this girl are treated as noun phrases (NP), very nice, quite nice, as adjective phrases (AdjP), and in class, with parents, from work, as prepositional phrases (PP). Consequently, the words came out of the class with her parents, are treated as dependent on the verb phrase (VP). The way the phrase is structured is done with 
the corresponding symbols for each word of the sentence.

The two basic concepts of transformative grammar are deep structure (DS), which provides a detailed reflection of syntactic structure, and surface structure (SS), which provides a more concise and less detailed overview ( (Saint-Jacques, 1967; Lakoff, 1969; Partee, 1975; Broderick, 1975; Radford, 1988; Ohalla, 2001). Broderick also introduced the idea that deep structure is the product of the application of the phrase rules, while in order to achieve surface structure the transformations to deep structure are necessary Therefore, according to him, transformations are steps necessary for the obtainment of surface structure (1975). In the same book, he points out that if more than two transformations occur within a sentence, their placement should follow a particular order. This is especially applicable with the passive form and the position of two opposites within the same sentence. According to Topping (1970), the description of grammar at the level of structures arose as a result of transformative grammar's objective to describe the speaker's ability to express himself in his own language. One of the differences between deep structure and surface structure, according to him, is that the meaning of deep structure can be expressed by some surface structure, which differ from deep structure in form, a view also held by Langendon (1970).

Ohalla (2001) points out that the grammatical functions of categories, such as the subject, predicate or object should not be confused with the labelling of categories, such as noun phrase, verb phrase, noun, verb, etc. Transformations, after which the theory is named, are essential in the conception of grammar, because as Radford (1988) points out, they facilitate the formation of different sentences, such as passive forms, interrogative forms, reinforcing phrases, etc., according to their relevant rules (Ohalla, 2001). Transformational theories treat connections as participants in the creation of individual sentences, and consequently, of structure.

In his article "On so-called pronouns in English", Postal (1970) makes an analysis of the deep structure of pronouns and their transformative derivatives. He argues that the notion "part of speech" refers to the components of the structure of the phrase superficially. Each part of speech in surface structure can have a deep structure counterpart with completely different syntactic features.

The argument that overloading the rules of phrase structure can lead to duplication of information is followed by the suggestion on limiting them to a set of principles in order to preserve meaning (Goldberg, A. 1995) or eliminating some of them altogether. This subsequently led to the birth of the X-bar theory (Ohalla, 2001).

Scholars such as Partee (1975) have also proposed the combination of transformative grammar with Montag grammar, according to which "the syntax of a language is the repetitive and simultaneous definition of the syntactic categories of a language, including the special category of the (transformative) T-phrase or formula" (p. 212).

From a computational perspective, according to Moyne (1967), transformational grammar consists of the generative component and two interpretative components. The generative component produces structures which are explained by interpretative components. The semantic component maps deep structures into semantic interpretations; the morpho-phonemic component divides surface structures according to phonetic sounds. The generative component consists of the phrase structure which produces deep structure, the lexicon, which puts words into the deep structure, and the transformative component, which converts deep structure into surface structure.

\section{Government and binding theory}

Efforts to improve approaches and thoughts in transformative grammar have led to the emergence of theories which have dominated in different periods. Chomsky originally used the terms Government and Binding to refer to separate theories. He expressed the idea of combining them in lectures held in Pisa, which he later summarized in his book "Lectures on Government and Binding: Lectures of Pisa" (1988).

Chomsky points out that according to this theory, the key word in a phrase "directs or commands the words dependent on it within the same phrase" (1988, p. 162). Furthermore, he argues that this can also happen at the structure level. The major notion of Government is the connection between the main word (head) of the construct and the words depending on it (complement). Chomsky defines the government relation as follows:

" $\beta$ is the governing category for $\alpha$ only and only if $\beta$ is the smallest category to which $\alpha$ belongs, governing $\alpha$, and which can intervene with $\alpha$ as a subject" (1988, p. 220).

His definition of the "dependent category" goes in this way:

" $\beta$ is a category dependent on $\alpha$ only and only if $\beta$ is the smallest category where $\alpha$ is a part and subject that can intervene with $\alpha "$. 
The word Binding in this theory deals with the relationship between anaphors, pronouns, nouns, etc., and the preceding words, that is, with the words on which they depend (Chomsky, 1988; Ohalla, 2001). The main principle of Government/Binding is: $\alpha$ depends on $\beta$ only and only if $\alpha$ and $\beta$ refer to the same object, and if $\beta$ commands $\alpha$. Consequently, in the sentence John read his book, if the word his refers to the name John, then it can be said that we have the application of the theory of Government, that is, the word his is commanded by the word John. But if his does not refer to the word John, then we have no interdependent relationship (Chomsky, 1988).

Chomsky considers the government and binding theory a successful approach to the dependency theory, as it offers solutions to the empirical and conceptual problems that emerged in the earlier version of the theory. The classical format for the representation of syntax structure according to the GB theory, is the T-model with three levels of representation: deep structure, surface structure and phrase structure.

\section{The minimalist program}

In the preface to his book 'The Minimalist Program" (2015a), Chomsky argues that the minimalist program is not a theory but a program otherwise known as minimalism, by which the founders have tried to formulate a (perfect) solution to the definition of language and its phenomena from a perspective similar to universal grammar but with a simplified and uncomplicated formulation. This program developed quite naturally after clarifying the ideas of the principles-parameters framework, an approach which claims that there are no specific rules or grammatical constructs for each language, but there are universal principles and different ways of applying them. Chomsky points out that in this approach "traditional grammatical constructs are treated as taxonomic phenomena, that is, summaries of structures with features that come as a result of the interaction between fixed principles and predetermined parameters in one way or another" (p. 117).

If language as a competence complemented the proposals made by the PM theory, then the answer to the question "how perfect is language?" would be that language is unique among cognitive systems and in the organic world.

The economic principles of the minimalist program apply both in representations, where each symbol must be interpreted by means of rules that do not depend on language and the phrase must be shortened to the maximum, and in derivatives, where the issue is a little more complicated as maximum reduction of derivatives is not always possible. Representation takes place on two levels, logical and phonetic, in an attempt to eliminate deep and surface structures (Ouhalla, 2001). Let us explain the theory using Chomsky's own example with lexicons. Each word has three sets of features: phonological, semantic, and formal, and when one feature is highlighted, the others are eliminated; for example, when we talk about the word airplane as a summary of formal features, the phonological and semantic components are excluded (2015b). The features of each component, again according to Chomsky, range from explicit and implicit to optional or strong (dominant). The latter is the point where the difficulty of elimination arises: the dominance of the trait can make the derivative indelible or the trait must be eliminated without becoming part of a wider structure.

According to Freidin (2007), minimalism makes a reformulation of some basic constructs of syntactic theory including phrase structure and transformations, driven by the assumption that all types of constructs must meet the criterion of conceptual necessity. As for the economics of representation, after a detailed analysis in the same book, Chomsky concludes that the theory of phrase structure can even be totally eliminated (2015b).

\subsection{Transformational Grammar and Second Language Teaching}

At the time when transformational grammar was at its peak, many studies researched its role in second language teaching. In an experiment with his English language students, Ney (1965) concluded that using transformative grammar in the classroom improves students' ability to use acceptable English sentences and patterns. This, he argues, is achieved through the type of information that transformation grammar provides to the language user.

Topping (1970) also holds the view that although not all transformation grammar principles are applicable and necessary (for example, the continuous practice of converting surface structure to deep structure) in learning a foreign language, language teachers should be able to "structure the language they teach students from a transformative perspective" (p. 43). Another argument he makes is with regard to the application of TG principles in language learning at the elementary level. Almost all foreign language textbooks start with simple words and structures and if this is the principle, that is, to move from the simple to the complex, then, he argues, the rules of phrase structure can help us determine what is simple and what is complicated. Let's take a look at the examples he uses. 
a John can throw the ball.

b John will throw the ball.

c John threw the ball.

If we asked a language teacher, for him/her the simplest sentence is $2 \mathrm{c}$, meanwhile, according to transformational grammar principles, it is more difficult as it needs two transformations: that of tense and the elimination of the auxiliary part. As for the structures, she adds that the texts should include materials which emphasize the fact that in seemingly identical structures, the relationship between the components may be different. Therefore, we have surface structures that do not originate from the same deep structure as in Topping's examples (1970).

3 a He likes growing orchids. (ii) He likes to grow orchids.

$3 \mathrm{~b}$ He likes growing children. (ii) He likes children who are growing.

$3 \mathrm{c}$ He likes amusing stories. (ii) He likes stories that amuse him.

Meanwhile, Lakoff (1969) also shares the view that transformative analysis can be used in second language teaching to explain perhaps the opposite side of Topping's view, that is, seemingly different sentences or with different surface structures, but with similar deep structures. Lakoff explains the difference with two examples (p. 136):

a Bill cut the salami with a knife.

b Bill used a knife to slice the salami.

Both of these sentences have the same basic meaning, that is a similar deep structure but the ways used to express this meaning, that is the surface structure, are different.

Finally, it can be said that the transformative grammar principles can be used in the process of learning a foreign language, especially at the beginner levels, where there is a gradual transition from the simplest to the most difficult. However, this does not completely impede the application of the transformative grammar principle to higher levels, where the transformation of more complicated phrases is possible only if the learner knows more advanced transformational principles.

\section{COGNITIVE GRAMMAR}

Cognitive grammar is a grammatical approach within cognitive linguistics, which belongs to the functional tradition and, as the name suggests, it is primarily a theory of grammar. Cognitive grammar does not question the existence of grammar as a whole, but raises the claim that it has a symbolic nature. The perception of Langacker (2006), the main founder of this theory, about grammar is that it simply provides the speaker with a host of symbolic sources, including schematic templates that represent certain patterns within the system of complex symbolic structures. According to him, speakers use these symbolic units to assess the appropriateness of new expressions and uses, both their own and those of other speakers. He also points out that cognitive grammar addresses the nature of grammar and its relation to other dimensions of linguistic structure (2009).

In general, cognitive grammar proponents address language based on our perceptions and conceptions the world (Langacker, 1987; 1990; 2008, 2009; David, 2001. The basic principle of cognitive grammar is that lexicon and grammar form a classification consisting only of summaries of symbolic structures, which gives them an imaginary character. When using a certain grammatical structure or a morpheme, for communication reasons, we naturally choose a certain image to give shape to the perception of the created situation. In support of this view, Langacker (2006) points out that since different languages have different grammatical structures, the images and perceptions they evoke are also different.

Authors such as Taylor (2002) and Achard (2008a) further address the symbolic nature of language. Taylor explains that each linguistic expression is represented by the symbolic connection of the phonological structure with the semantic one as in the following figure (2002, p. 21):

The symbolic nature of language enables the communication of thought between people; as an integral part of language, but which cannot exist independently; grammar too with its symbolic nature, is consequently meaningful and has an important, though not essential, role in carrying meaning.

Another suggestion Langacker (2001) makes is that there is a natural and intrinsic connection between cognitive grammar and discourse, and in order to make a clearer and more complete description of 
interaction and discourse, cognitive perspectives are needed. He also points out that the understanding of grammatical categories is motivated by visual perception (1987).

The grammatical and lexical subsystems of language serve to specify different aspects of a sentence, which Talmy (2008) summarizes as "cognitive representation". According to him, the grammatical elements define most of the cognitive representation structure, reflecting a perceptual framework or a basic structure of what is expressed through lexicon. Consequently, widely seen, grammar constitutes the main perceptual determinant within a language or structure.

\subsection{Cognitive Grammar and second Language Teaching}

Since cognitive grammar explains the semiological function of language, that is, the symbolic connection between meaning and form, the contribution of cognitive grammar to foreign language learning can be given by integrating its discretionary views with already established models of second language learning pedagogy. Based on cognitive grammar's principle that in our linguistic knowledge the rules of grammar coexist with specific examples, Achard (2008b) explains how cognitive grammar can be integrated into the Natural Approach, citing three steps for teaching grammar. The first step is to select a specific grammatical construct, the second step is to structure an activity that includes the selected model, and the third step is to plan a series of activities that enable practicing it.

The fact that cognitive grammar emphasizes the symbolic nature of linguistic expressions gives the language teacher the opportunity to focus on the acquisition of grammatical structures, which helps the student to perceive the form of these structures. It is precisely the symbolic nature of grammar that avoids the mechanical learning of grammatical knowledge and helps to acquire it in a practical way. According to Achard (2008a), since cognitive grammar is based on the concept of language use, it plays a key role for foreign language teachers, as it presupposes that students benefit from the exposure they have to authentic language. In methodological terms, knowing the meaning of grammatical constructs creates the possibility of teaching grammar in accordance with the principles of contemporary communicative models of language pedagogy (Achard, 2008b). Archard supports this view with the idea that when the principles of cognitive grammar are applied, the student is placed at the centre of communication, which is the main purpose of teaching. The pedagogical challenge lies in involving L2 learners in challenging situations where they have to make language choices similar or almost similar to native speakers'.

\section{CONSTRUCTION GRAMMAR}

Construction grammar was introduced as a theory by Fillmore and his students in the early 1980s. It does not make a definite separation of lexicon and syntax; on the contrary, lexical and syntactic constructs are considered as structures that unite and relate form to meaning (Goldberg, A.,1995; 2005; Pitel, 2006; Micelli, 2006; Sogaard, 2006; Ostman \& Fried, 2005). "Grammatical construct is any kind of syntactical model that has one or more functions in language, along with the contribution it makes to the meaning and use of the structure to which it belongs" (Fillmore, 1988, p. 36). Each construct has internal properties, which means the description of the composition / structure of the construct, and external properties, which means the features of the structure as a whole (Fillmore, 1988). It is precisely the centralization of the construct that distinguishes constructive grammar from other traditional generative theories (Goldberg, A., 2005).

Constructive grammar theorists attempt to explain all the constituent constructs of language and not just those that are considered to be the essence of grammar. They also try to describe the conditions under which a construct can be used appropriately (Goldberg, 1995). According to Fillmore (1988), the grammar of a language is a repertoire of constructs and principles that guide the placement and interconnection of these constructs.

In her book Constructive Approaches to Structure Argumentation, Goldberg (1995) outlines some advantages of the constructive approach to argumentation structure. One of the advantages of constructive grammar is that it avoids presenting the unacceptable meaning of some verbs to explain their meaning in specific cases. Let us see the following example:

5) He sneezed the napkin off the table.

A lexico-semantic theory would explain it this way: the verb sneeze has a meaning with three arguments, $X$ makes $Y$ move $Z$ by sneezing. Whereas according to the constructive approach, there is no need to define a special and unique meaning of the word sneeze in the given sentence. The right adverb does not depend directly on the arguments of the verb but on the particular construct, and as a result, the meaning depends on the construct. 
Another advantage of constructive grammar is avoiding the notion of circuit. According to this circuit, the verb has a central role, so it determines the number and type of arguments that will be located within the same sentence; meanwhile, the constructive approach ignores this argument and holds that the verb has a main meaning and some basic meanings, which must be integrated into the meaning of the construct (Goldberg, 1995.

Unlike transformative grammar, constructive grammar addresses grammatical connections as a whole and not as active in creating structures. The categories that name the units of the structure include a range of complex information rather than just the basic categories. Constructive grammar allows direct representation of the properties of subordinating components without using confusing symbols and terms such as low level or high level structure (Fillmore, 1988). Constructive grammarians do not separate grammatical patterns from pragmatic or semantic purposes but describe them simultaneously.

Constructive grammar has also been used by computational linguists. Many researchers have tried to base computational linguistics precisely on constructive grammar (Micelli, 2006; Pitel, 2006; Sogaard, 2006).

As a psychological theory, constructivism derives from the cognitive sciences, in particular, Piaget's latest work. Although in the beginning this theory described learning and teaching based on the stages of cognitive development, later Piaget and his followers began to focus on the learning mechanism as a process that enables the creation of new structures and new constructs. Moreover, many authors (Ostman \& Fried, 2005; Goldberg, 1995) hold the view that constructive grammar and cognitive grammar are interrelated. Leino (2005) goes further claiming that they complement each other.

\subsection{Construction Grammar and Second Language Teaching}

Since constructivism is not a theory of teaching, but a theory of learning, what can be derived from it are not genuine strategies that can be used in teaching, but principles of learning. As Fosnot and Perry (2005) point out, these principles are valid and should be kept in mind whenever we reformulate educational practices. These principles are presented below in order to then make a presentation of their application in foreign language teaching.

a) First of all, learning is not the result of development but development itself, so the teacher should leave students space to formulate questions and hypotheses, check their validity and be able to defend and argue them.

b) Errors should be considered a result of student perception and as such should not be avoided or minimized. On the contrary, teachers should create such situations in which the student has the opportunity to explore both positive and contradictory possibilities.

c) Since reflective abstraction is the driving force of learning, it should be encouraged by creating spaces for reflection. This can be accomplished through the exchange of experiences in multi-symbolic written forms and in discussions.

d) Dialogue within the community develops advanced thinking and the class should be considered a community engaged in activities, reflection and conversation. Students are responsible for justifying, arguing, and communicating their ideas in the classroom.

e) Learning is a product of activity and self-organization, and consequently leads towards the development of structures. The construction of progressive structures brings about the birth of great ideas, which are necessary for the further development of society (Fosnot \& Perry, 2005).

Most of the cognitive grammar principles mentioned above can be easily applied in the second language learning context. Items, a, c, and d are directly related to the development of the learners' writing and speaking skills and their application has a positive effect on their development. Error correction (b) is a highly debated issue due to the impact it has on teaching both form and lexicon. As for item e, there is a reciprocal correlation with second language learning. On the one hand, processes of engagement and self-organisation help in second language learning; on the other, second language learning is not an unimportant contributes to birth of new ideas and the steps towards development.

Goldberg and Casenhiser (2008) claim that in order for children to be able to understand and use a language, they need to become familiar with how meaning is expressed, that is, they need to know and learn the constructs used to express meaning. Associating structural patterns with meaning is an essential part of learning a second language. Based on various studies conducted with children and adult native English speakers, they have reached the conclusion that results may have an impact on foreign language pedagogy. They suggest the presentation of particular input with as many typical examples as possible while also taking 
into account other factors that might influence the classroom environment (Goldberg \& Casenhiser, 2008).

Achard (2008b) argues that most language guides present grammar rules as parts/features of the target language rather than a product of the language chosen by the speaker, which contradicts the principle of constructive learning. He points out that shifting the focus to the speaker (in this case, the learner) requires a transition from simply introducing linguistic structures and patterns to learning how these patterns should be adapted to certain situations. In this respect, it should be borne in mind that these types of activities are feasible at all levels. Achard emphasizes that flexibility in constructive expression should only be part of instruction with intermediate or advanced level students.

\section{CONCLUSION}

Different theories of grammar have been proposed over the years and they have studied it from two major perspectives. While the formal perspective focused on grammar as a set of rules, the functional perspective considered it a source for the creation of thought leading to different forms of communication. These different schools of thought have also had their impact on second or foreign language instruction; the formal approaches mainly influenced and contributed to the instruction of grammar and various grammar phenomenon as basic units of language; the functional approaches mostly affected the instruction of grammar phenomena for communicative purposes. This paper gave an overview of three grammar theories, transformational grammar, cognitive grammar and construction grammar, and their influence and applicability in EFL/ESL instruction.

Grammar instruction whether directly or indirectly is already an inseparable part of second language education. While grammar knowledge and grammar teaching skills are necessary for effective grammar instruction, the need also arises for EFL/ESL teachers' awareness of and their familiarity with the theories of grammar in order for them to be able to adapt and use them effectively and practically in the instruction of grammar. In addition, awareness of the peculiarities of each theory may contribute to a more suitable choice according to the learners' needs and the grammar constructs. This would not mean applying only one theory and totally disregarding the rest; on the contrary, awareness of the peculiarities and differences between the theories should lead to implementation of the most convenient theory and even to an alternation of principles from different theories.

\section{REFERENCE LIST}

Archard, M. (2008a). Teaching construal: Cognitive pedagogical grammar. In P. Robinson, Handbook of cognitive linguistics and second language acquisition (pp. 432-455). New York: Tazlor \&Francis.

Archard, M. (2008b). Grammatical instruction in the natural approach: A cognitive grammar view. In M. Archard, \& S. Niemeier, Cognitive linguistics, second language acquisition and foreign language teaching (pp. 165-194). Berlin, New York: De Gruyter Mouton.

Broderick, P. (1975). Modern English linguistics: a structural and transformational grammar. New York : Thomas Y Crowell Company.

Chomsky, N. (1966). The current scene in linguistics: present directions. College English 27(8), 587-595, https://www.jstor.org/stable/374695?seq=1\#metadata_info_tab_contents.

Chomsky, N. (1976). Studies on Semantics in Generative Grammar. The Hague, Paris: MOUTON.

Chomsky, N. (1988). Lectures on Government and Binding: Lectures of Pisa. Dordrecht: Foris.

Chomsky, N. (2015a). The minimalist program, a 20th anniversary edition. MIT Press.

Chomsky, N. (2015b). Aspects of the theory of syntax (Vol. 11). London: MIT Press.

David, L. (2001). Cognitive linguistics: An introduction. New York: Oxford University Press.

Ellis, N. (1998). Emergentism, connectionsism and language learning. Language Learning, 48(4), 631-664.

Fillmore, C. (1988). The mechanisms of "construction grammar". Annual Meeting of the Berkeley Linguistics Society (pp. (Vol.14) 35-55). Berkeley: Berkeley Linguistics Society . 
Fosnot, C. T., \& Perry, R. (2005). Constructivism: A psychological theory of learning. In C. T. Fosnot, Constructivism: THeory, perspectives and practice, 2nd ed. (pp. 89-120). New York, London: Teachers College Press, Columbia University.

Freidin, R. (2007). Generative grammar: Theory and its history. New York: Routledge.

Givon, T. (2011). Ute reference grammar. Amsterdam, The Netherlands: John Benjamins Publishing Company.

Goldberg, A. (1995). Constructions: A construction grammar approach to argument structure. London: University of Chicago Press.

Goldberg, A. (2005). The cognitive grounding of construction grammar. In J. Ostman, \& M. Fired, Construction grammars: Cognitive groundings and theoretical extensions (pp. 17-43). Amsterdam: John Benjamins Publishing.

Goldberg, A., \& Casenhiser, D. (2008). Construction learning and second language acquisition. In P. Rpbinson, \& N. Ellis, Handbool of cognitive linguistics and second language acquisition (pp. 197215). New York: Taylor \& Francis.

Greenbaum, S., \& Nelson, G. (2009 ). An introduction to English grammar. Pearson Education.

Halliday, M. A. (1994). An introduction to functional grammar, 2nd edition. London: Edward Arnold Limited.

Hudddleston, P., \& Pullum, G. (2007). A student's introduction to English grammar. New York : Cambridge University Press .

Hurford, J., \& Hurford, J. (2012). The origins of grammar: Language in the light of evolution II (Vol.2). Oxford University Press.

Kaplan, R., \& Bresnan, J. (1995). Lexical functional grammar: a fromal system for grammatical representation. In M. Dalrymple, R. Kaplan, J. Maxwell III, J. Maxwell, \& A. (. Zaenen, Formal issues in lexical functional grammar, No 47 (pp. 29-130). Center for the study of language .

Lakoff, R. (1969). Transformational grammar and language learning . Language learning, 19(2), 117-140.

Lanagacker, R. (2009). Investigations in cognitive grammar. Berlin : Mouton de Gruyter.

Langacker, R. (1987). Foundations of cognitive grammar, Vol.1 Theoretical prerequisites. Stanford: Stanford University Press.

Langacker, R. (1990). Foundations of cognitive grammar: Descriptive application, Vol.2 . Stanford: Stanford University Press.

Langacker, R. (2001). Discourse in cognitive grammar. Cognitive llinguistics, 12(2), 143-188.

Langacker, R. (2006). Cognitive grammar:Introduction to concept, image and symbol. In D. Geerarets, Cognitive linguistics: Basic readings (pp. 29-68). Berlin: Walter de Gruyter GmbH\&Co.

Langacker, R. (2008). Cognitive grammar: A basic introduction. Oxford : Oxford University Press.

Langendoen, D. T. (1970). The accessibility of deep structures . In R. Jacobs, \& P. Rosenbaum, Readings in English transformational grammar (pp. 99-106). Massachusetts: Gin and Company.

Leino, J. (2005). Frames, profiles and constructions: two collaborating CGs meet Finnish Permissive Construction. In O. Ostman, \& M. Fried, Construction Grammars: Cognitive grounding and theoretical extensions (pp. 89-120 ). Amsterdam: John Benjamins Publishing .

Lock, G. (1996). Functional English grammar: an introduction for second language teachers. Cambridge: Cambridge University Press.

Mathiessen, C., \& Halliday, M. (2009). Systemic funstiona grammar: a first step into theory. https://www.researchgate.net/profile/Christian-

Matthiessen/publication/265398862_SYSTEMIC_FUNCTIONAL_GRAMMAR_A_FIRST_STEP_INT O THE THEORY/links/54b513ef0cf28ebe92e4bacf/SYSTEMIC-FUNCTIONAL-GRAMMAR-AFIRST-STTEP-INTO-THE-THEORY.pdf.

Micelli, V. (2006). Searching for grammar right. The third workshop on scalable natural language understanding (pp. 57-64). New York: The assocciation for computational linguistics. 
Moyne, J. (1967). An introduction to transformational grammar. International journal of computer mathematics, 2(1-4), 169-181.

Mukherji, N. (2010). The primacy of grammar. Massachussets: MIT Press.

Nathan, G. (2008). Phonology: A cognitive grammar introduction (Vol.3). John Benjamins Publishing .

Ney, J. (1965). Transformational grammar in a Ryudai Classroom. Language learning, 15(1-2), 51-59.

Ohalla, J. (2001). Introducing transformational grammar: From principles and parameters to minimalism, 2nd edition. Beijing : Edward Arnold Lmited .

Ostman, J., \& Fried, M. (2005). The cognitive grounding of construction grammar. In J. Ostman, \& M. Fried, Construction Grammars: Cognitive grounding and theoretical extensions (p. 1013). Amsterdam: John Benjamins Publishing .

Partee, B. (1975). Montague grammar and transfromational grammar. Linguistic inquiry, 6(2), 27-40.

Pitel, P. (2006). Scaling construction grammar up to production systems: the situated constructional interpretation model. The third workshop on scalable natural language understanding (pp. 49-58). New York: The associaton for computational linguistics.

Postal, P. (1970). On the so-called pronoouns in English. In R. Jacobs, \& P. Rosenbaum, Readings in transformational grammar (pp. 56-82). Massachusetts: Gin and Company.

Radford, A. (1988). Transfromational grammar: a first course. Cambridge : Cambridge University Press.

Saint-Jacques, B. (1967). Some observations about transformational grammar. La linguistique, 3(2), 27-40.

Sogaard, A. (2006). Embodied construction grammar as Izyered modelled languages. The third workshop on scalable natural language understanding (pp. 65-73). New York : The association for computational linguistics .

Talmy, L. (2008). Grammar construal: the relation of grammar to cognition. In D. Geerartes, Cognitive linguistics:Basic readings (pp. 69-208). Berlin: De Gruyter Mouton.

Taylor, J. (2002). Cognitive grammar. Oxford : Oxford University Press.

Topping, D. (1970). Some implications of transformational grammar for language teaching. RELC Journal, 1(1), 37-49. 